\title{
Use of Neostigmine for the Management of Drug Induced Ileus in Severe Poisonings
}

\section{Dr Betty Chan, MBBS FACEM PhD a, Professor Ian Whyte, MBBS FRACP FRCPE bc, Professor Andrew Dawson, MBBS Dip Epid FRCPE FRACP bc, Dr Michael Downes, Mb ChB b}

\author{
a Departments of Clinical Toxicology, Prince of Wales Hospital \& Westmead Hospital, Sydney, Australia \\ b Department of Clinical Toxicology \& Pharmacology, Newcastle Mater Misericordiae Hospital, Newcastle, Australia \\ c Discipline of Clinical Pharmacology, University of Newcastle, Newcastle Australia
}

\begin{abstract}
Introduction: Effective whole bowel irrigation may be difficult in the presence of drug-induced ileus. Neostigmine, which inhibits the enzymatic degradation of acetylcholine, has been suggested to improve drug-induced ileus. We present two poisoning cases in which neostigmine was used to facilitate gut decontamination complicated by ileus.

Case Reports: A 47-year-old woman, after overdose with sodium valproate, venlafaxine, and ibuprofen, developed ileus that prevented whole bowel irrigation. Neostigmine, $2.5 \mathrm{mg}$ intravenously followed by $1.25 \mathrm{mg}$ three hours later, led to improved bowel transit and successful whole bowel irrigation. A 25-year-old man developed ileus after overdose with venlafaxine, dothiepin, and ethanol. Neostigmine administration led to improved intestinal motility and successful whole bowel irrigation.

Discussion: We demonstrate facilitated gut decontamination temporally associated with administration of neostigmine in two patients judged to have drug-induced ileus following overdose. No significant adverse events related to neostigmine were observed.
\end{abstract}

\section{INTRODUCTION}

The management of life threatening poisonings from slow release medications often poses a clinical challenge to physicians. Multiple doses of activated charcoal may be used for drugs (such as theophylline and carbamazepine) that have a significant enterohepatic circulation. For extended release medications and drugs that do not benefit from repeated doses of activated charcoal, whole bowel irrigation has been recommended for gastrointestinal decontamination [1]. However, whole bowel irrigation is not feasible in patients who develop drug induced ileus. A number of randomized studies have demonstrated that neostigmine can be used to manage patients with colonic ileus [2-3]. Neostigmine has been successfully used in a patient with anticholinergic drug induced ileus [4]. We will present two cases of poisoning complicated by ileus where neostigmine was used to facilitate gut decontamination.

\section{CASE 1}

A 47-year-old woman (weighing $70 \mathrm{~kg}$ ) was presented with a history of having ingested $190 \times 200 \mathrm{mg}$ (38 g) of sodium valproate, $53 \times 150 \mathrm{mg}$ (7.95 g) of venlafaxine, and $12 \times 200 \mathrm{mg}$ ( $2.4 \mathrm{~g}$ ) of ibuprofen 3 hours before presentation to a peripheral hospital. On examination, she was haemodynamically stable with a GCS 15. Neurological examination revealed hyperreflexia

Keywords: neostigmine, ileus, venlafaxine, overdose

Corresponding Author: Betty Chan, PhD, Department of EM, Royal Prince Alfred Hospital, Missenden Road, Camperdown 2050 Nsw, Australia. Email: bschan@ozemail.com.au 
with clonus in the lower limbs. She was treated with $50 \mathrm{~g}$ of activated charcoal. Eleven hours post ingestion, she became haemodynamically unstable with a systolic blood pressure of $85-90 \mathrm{~mm} \mathrm{Hg}$, a sinus tachycardia of $110-120$ beats per minute, and a fluctuating GCS between 8 and 12. The patient was resuscitated with intravenous fluids, norepinephrine infusion $(4 \mu \mathrm{g} / \mathrm{kg} / \mathrm{min})$, intubated, and transferred to a nearby referral hospital. On arrival at the Intensive Care Unit, she was stable and the initial valproate concentration was $2468 \mu \mathrm{mol} / \mathrm{L}$ (350-700 $\mu \mathrm{mol} / \mathrm{L}) 9 \mathrm{hrs}$ post ingestion. Her serum ammonia level was $100 \mu \mathrm{mol} / \mathrm{L}(15-50 \mu \mathrm{mol} / \mathrm{L})$. Her liver function tests and acid base status were normal. She was treated with haemodialysis for 5 hours because the patient had an ileus and was showing some signs of severe valproate toxicity. The valproate concentration came down from 1949 to $816 \mu \mathrm{mol} / \mathrm{L}$ during haemodialysis (Figure 1).

Attempts were made to commence whole bowel irrigation, but the patient had developed an ileus. She was given $2.5 \mathrm{mg}$ neostigmine IV over 1 minute. A bowel movement was observed within 5 minutes, and pill fragments were seen mixed with the bowel motion. A transient hypotension was observed, but it responded to intravenous fluid. A second $1.25 \mathrm{mg}$ dose of neostigmine was given 3 hours after the first dose to continue the bowel movement. The whole bowel irrigation was completed after 24 hours and the patient was extubated the next morning.

\section{CASE 2}

A 25-year-old man was presented to a peripheral hospital with a history of having ingested $90 \times 150 \mathrm{mg}$ of venlafaxine $(13.5 \mathrm{~g})$; $30 \times 25 \mathrm{mg}$ of dothiepin $(750 \mathrm{mg}$ ); and ingestion of some alcohol. On initial assessment, he was alert and orientated, with a
HR of 148/min and a BP of 150/66 mm Hg. Soon after arrival at the Emergency Department, he developed a grand mal seizure and was treated with $3 \mathrm{mg}$ midazolam IV. He was intubated and given activated charcoal. He was acidotic with a $\mathrm{pH}$ 7.3, a $\mathrm{pCO}_{2}$ $51 \mathrm{~mm} \mathrm{Hg}$, and a $\mathrm{BE}-1 \mathrm{mmol} / \mathrm{l}$. He was given $\mathrm{NaHCO}_{3}$ for prolonged QRS on an ECG. He was thought to have continuous seizure activity and was managed with phenobarbitone infusion. He was transferred to a tertiary referral hospital. On arrival at the ICU, he was noted to have had dilated pupils, normal active bowel sounds, and was hyperreflexic with non-sustained clonus. He was commenced on whole bowel irrigation with polyethylene glycol (1L/hr). Ten hours after admission to the hospital, he was noted to have had abdominal distension with reduced bowel sounds and an ileus. He had not passed any faecal fluid, and polyethylene glycol was being passively regurgitated. The phenobarbitone and morphine infusion were ceased. He was given $2.5 \mathrm{mg}$ neostigmine IV over 20 minutes. At 10 minutes his bowel sounds were noted to be active, and he passed a large amount of rectal effluent. This subsequently continued with a rate of $1 \mathrm{~L} / \mathrm{hr}$ rectal effluent, with a mixture of pills and fluid. He continued to be acidotic with a $\mathrm{pH} 7.26$, a $\mathrm{pCO}_{2} 40 \mathrm{~mm} \mathrm{Hg}$, and a $\mathrm{BE}-7.8$. He was treated with $\mathrm{NaHCO}_{3}$. Whole bowel irrigation was continued for 48 hours and was ceased when pill fragments were no longer visible. Soon after, he was extubated.

\section{DISCUSSION}

Colonic ileus is a clinical picture of a mechanical obstruction in the absence of any demonstrable occlusion of the gut. This is first described by Ogilvie [5]. It can either be due to sympathetic overactivity or parasympathetic suppression. The use of neostigmine for the management of colonic ileus or acute colonic

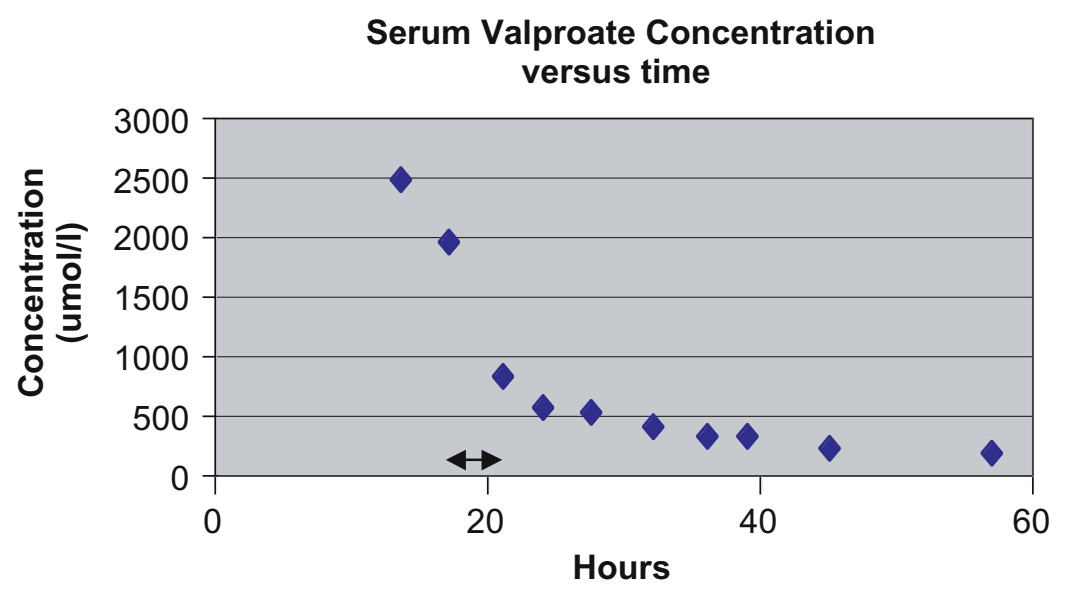

$\leftrightarrow$ Haemodialysis for 5 hours

Figure 1. Serum Valproate Concentration versus Time. 
pseudo-obstruction has been well documented [2-4]. In both of our patients, it was considered critically important that they should have an adequate bowel washout, but the ileus made a bowel washout impossible. The use of neostigmine produced an impressive response within 5 minutes and had minimal adverse effects. With the first patient, a second dose was required because of the drug's short duration of action. We postulate that the clear temporal response of clinical ileus to the administration of neostigmine in both patients is evidence of its efficacy. In this clinical situation, neostigmine successfully facilitated whole bowel irrigation.

Neostigmine is a peripheral cholinesterase inhibitor. It induces smooth muscle contraction and propulsion, perhaps by stimulating the muscarinic receptors in the myenteric plexus. It has a volume of distribution at $0.5-1 \mathrm{~L} / \mathrm{kg}$ and a plasma half-life of 20-60 minutes after intravenous administration. Side effects include salivation, nausea, vomiting, abdominal pain, bradycardia, hypotension, and bronchospasm. During neostigmine infusion, patients should have cardiac monitoring with atropine available. Contra-indications include an $\mathrm{HR}<60 / \mathrm{min}$ and an $\mathrm{SBP}<90 \mathrm{~mm} \mathrm{Hg}$ if patients are on beta-blockers, acidotic, or have had recent myocardial infarct. Both of our patients were normotensive when neostigmine was administered. Inotropic support was provided for the first patient. The second patient had an unclear cause of mild persistent acidosis, possibly related to the bicarbonate loss from the gut due to the previous whole bowel irrigation. Another potential danger is a bezoar [6] that causes a mechanical bowel obstruction. Strong peristalsis produced by neostigmine may result in colonic perforation. This may have to be ruled out with a water-soluble contrast enema before neostigmine is given.

A recent volunteer study by Amato et al. [7] was performed to evaluate the use of neostigmine and erythromycin as prokinetic agents to limit the gut absorption of a therapeutic adult dose of extended-release acetaminophen (1300 mg). When compared with the control phase, the study failed to demonstrate any difference in the elimination of acetaminophen by either neostigmine or erythromycin. The findings of the study cannot be extrapolated to patients who have taken a potentially fatal dose of extended release medications and who are receiving interventions known to reduce gastrointestinal transit time. While neostigmine may be shown to be ineffective in patients with normal gut motilities, it may have an important role in patients that have colonic pseudo-obstruction but who need to undergo whole bowel irrigation to remove remaining toxins in the gut.

Severe valproate toxicity occurs with overdoses exceeding $400 \mathrm{mg} / \mathrm{kg}$. Overdoses of sodium valproate can cause multiorgan failures that include paradoxical seizures, coma, cerebral edema, metabolic acidosis, bone marrow failure (leucopenia, thrombocytopenia), abnormal LFT (hyperammonaemia) and circulatory collapse. The management of severe sodium valproate poisoning includes supportive management, multiple dose activated charcoal-and (in patients who are unstable) haemodialysis or haemoperfusion is recommended. Haemodialysis may result in a four to five-fold decrease in elimination half life in overdose patients. In addition, dialysis can remove metabolic disturbances and valproic acid metabolites. In the first case, haemodialysis may not have been indicated because the literature suggests that a sodium valproate level $<5900 \mu \mathrm{mol} / \mathrm{L}$ can be successfully managed with conservative treatment [7]. The co-ingestion of a large dose of venlafaxine may have contributed to the haemodynamic instability [8].

The most common toxic symptoms for venlafaxine are seizures and excessive serotonin activity. Toxic symptoms include agitation, delirium, tremor, clonus, fever, and other symptoms. The toxicity usually appears within 6 hours for standard release poisoning, but it may be delayed for 12-15 hours in extended release poisoning. Although the mechanism of seizure activity is unclear, ingestion of $1 \mathrm{~g}$ of venlafaxine has been reported to cause seizures. Animal models suggest that the cardiotoxicity and QRS widening are due to $\mathrm{Na}^{+}$channel blockade [4]. Fatal and non-fatal ventricular arrhythmias have been reported with large ingestions of venlafaxine $(>7 \mathrm{~g})$.

Treatment of extended release venlafaxine is mainly supportive for seizure control and avoiding the use of sodium channel blocking drugs that can exacerbate cardiotoxicity. Some success has been reported with the use of sodium bicarbonate for the management of cardiac arrhythmias. Aggressive gut decontamination with activated charcoal and whole bowel irrigation is recommended for toxic doses of extended release preparations.

In both our cases, whole bowel irrigation was hampered by the presence of ileus induced by the poisonings. Both patients had ingested a potentially fatal dose of extended release venlafaxine. The first patient had a significant co-ingestion of valproate, and the second patient had a co-ingestion of dothiepin. Neostigmine appeared to reverse the ileus to allow gut decontamination to occur. Further studies are required to demonstrate the efficacy of neostigmine in the management of drug induced ileus in severe poisonings.

\section{REFERENCES}

1. Tenenbein M. Position statement: whole bowel irrigation. American Academy of Clinical Toxicology; European Association of Poisons Centres and Clinical Toxicologists. J Toxicol Clin Toxicol. 2000;38:689-690.

2. Ponec RJ, Saunders MD, Kimmey MB. Neostigmine for the Treatment of Acute Colonic Pseudo-obstruction. NEJM 1999;341:137-141.

3. Van der Spoel JI, Oudemans-van Straaten HM, Stoutenbeek CP, Bosman RJ, Zandstra DF. Neostigmine Resolves Critical Illness Related Colonic Ileus in Intensive Care Patients with Multiple Organ Failure-a Prospective, 
Double-Blind, Placebo Controlled Trial. Int Care Med.

2001;27:822-827.

4. Isbister FK, Oakley P, Whyte I, Dawson A. Treatment of Anti-cholinergic Induced Ileus with Neostigmine. Ann Emerg Med. 2001;38:689-693.

5. Olgilvie H. Large-Intestinal Colic due to Sympathetic Deprivation. A New Clinical Syndrome. BMJ. 1948;2:671-673.
6. Brubacher JR, Levine B, Hoffman RS. Intestinal pseudoobstruction (Ogilvie's syndrome) in theophylline overdose. Vet Hum Toxicol. 1996;38:368-70.

7. Amato CS, Wang RY, Wright RO, Linakis JG. Evaluation of Promotility Agents to Limit the Gut Bioavailability of Extended-Release Acetaminophen. J Toxicol Clin Toxicol. 2004;42:73-77. 